\title{
Synthesis and Phytotoxicity of 4,5 Functionalized Tetrahydrofuran-2-ones
}

\author{
Gabriela C. Resende, ${ }^{a}$ Elson S. Alvarenga, ${ }^{*, a}$ Juan C. G. Galindo ${ }^{b}$ and \\ Francisco A. Macias $^{b}$ \\ a Departamento de Química, Universidade Federal de Viçosa, 36570-000 Viçosa-MG, Brazil \\ ${ }^{b}$ Grupo de Alelopatía, Departamento de Química Orgánica, Facultad de Ciencias, \\ Universidad de Cádiz, 11510 Puerto Real, Cádiz, España
}

\begin{abstract}
Neste trabalho relatamos uma síntese versátil de quatorze $\gamma$-lactonas análogas, dentre as quais nove são inéditas, a partir do furfural prontamente disponível. A atividade fitotóxica dos compostos sintetizados foi avaliada in vitro pela influência no crescimento de coleóptilos de trigo. A maior parte das porcentagens de inibição foi pequena e não diferenciou do controle após a terceira diluição $\left(100 \mu \mathrm{mol} \mathrm{L}{ }^{-1}\right)$. Em geral, as lactonas $\alpha, \beta$-insaturadas apresentaram melhor atividade que as saturadas. Os compostos mais ativos a $1000 \mu \mathrm{mol} \mathrm{L}^{-1}$ apresentaram inibições de 51, 68 e 76\%. Os resultados indicam que, independentemente da saturação, a presença do anel $\gamma$-lactonônico é importante para a bioatividade, mas a sua presença não implica necessariamente boa potência.
\end{abstract}

In this work we report a versatile synthesis of fourteen $\gamma$-lactones all structurally related, nine of which are novel compounds, accomplished from the readily available furfural. The phytotoxic activity of the synthesized compounds was evaluated in vitro by the influence on the growth of wheat coleoptiles. The percentages of inhibition were mostly small and not statistically different from control after the third dilution $\left(100 \mu \mathrm{mol} \mathrm{L}^{-1}\right)$. In general, $\alpha, \beta$-unsaturated lactones presented better activities than the saturated ones. The most active compounds presented 51, 68 and $76 \%$ of inhibition in $1000 \mu \mathrm{mol} \mathrm{L}-1$. The results indicate that regardless of saturation, the presence of the $\gamma$-lactone moiety is important for the bioactivity, but their presence has no implications with potency.

Keywords: $\gamma$-lactones, wheat coleoptiles, herbicide, Triticum aestivum

\section{Introduction}

The interference caused by weeds is one of the main factors that affect agricultural productivity. By competing for light, moisture and nutrients the plants begin to influence the growth, development and productivity of the culture in which they settle, which may cause significant losses in production. ${ }^{1}$

Although chemical control is an efficient and economically feasible measure to ensure the integrity of crops, inadequate use of pesticides can lead to problems like the death of non-target organisms (including natural enemies) and contamination of soil, water, food and man. ${ }^{2}$ In addition, weeds can develop mechanisms of herbicide resistance, which in turn, requires the use of ever more powerful drugs and in greater quantities. ${ }^{3}$ In order to minimize such damage, more efficient, less toxic and less persistent active ingredients in nature has been developed. ${ }^{4}$

*e-mail: elson@ufv.br
Parasitic weeds are a serious problem in agriculture, causing large crop losses in many parts of the world. Witch weeds and broomrapes infestation can heavily damage crop plantations even before germination of the parasites. Strigolactones are produced via the carotenoid pathway of plants and have been isolated from a number of different plant species. Crop species resistant to one or more species of parasitic plants belonging to the genera Orobanche or Striga were developed. ${ }^{5}$

The $\gamma$-lactone moiety is found in many natural and synthetic compounds that have diverse biological activities: antibacterial, ${ }^{6}$ antitumor, ${ }^{7}$ anti-inflammatory agents, ${ }^{8}$ analgesics, ${ }^{9}$ antimalarial, ${ }^{10}$ fungicides,,${ }^{11}$ insecticides ${ }^{12}$ and herbicides (Figure 1) ${ }^{13}$ The ring of these compounds present diverse patterns of saturation and substitution and most of them have very large carbon skeletons. In addition to its natural abundance, many of these lactones have been used as intermediates for the synthesis of analogues. 


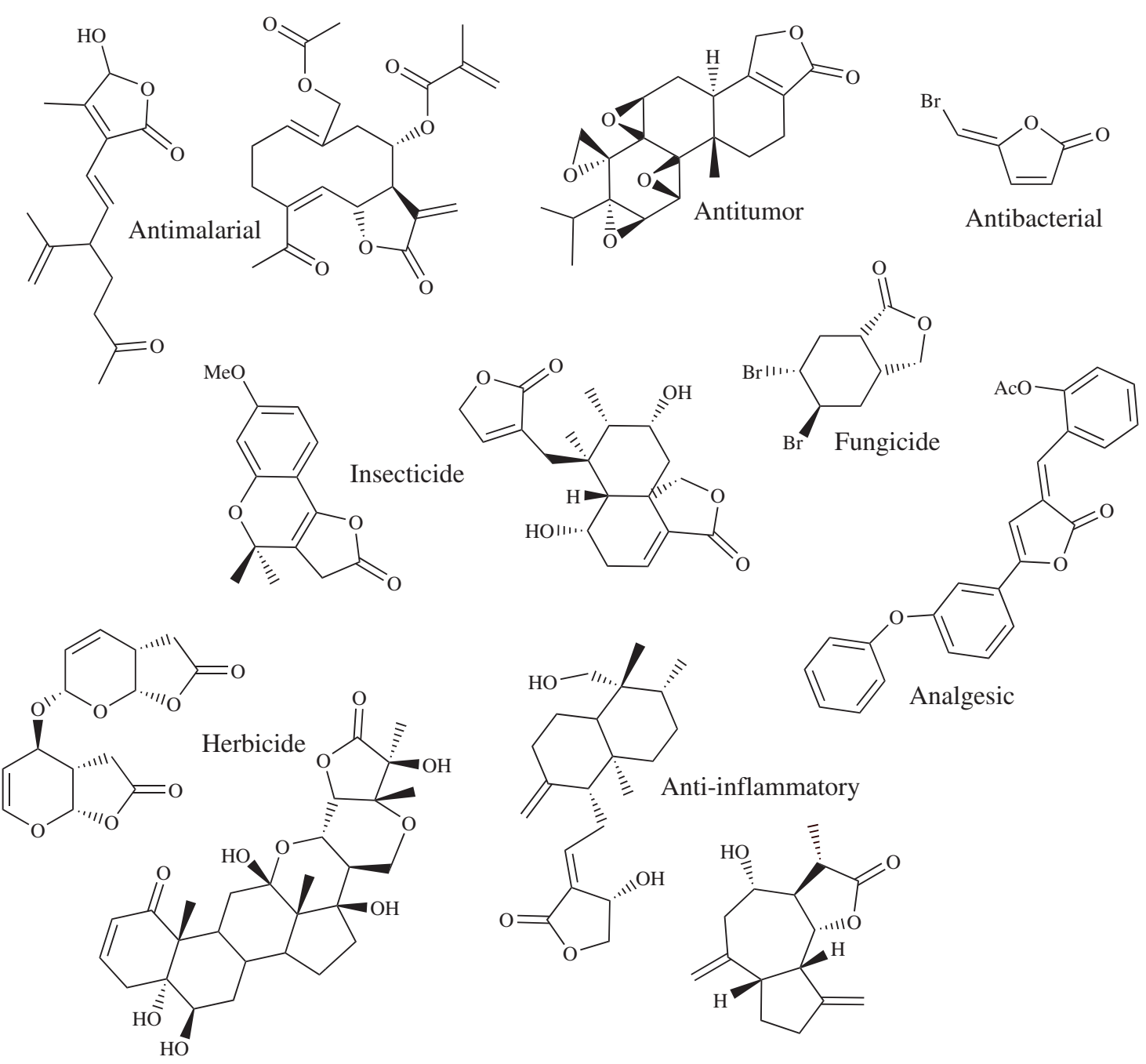

Figure 1. $\gamma$-Lactones and respective biological activities.

The haloenol lactones are useful in preventing or reducing herbicide resistance in plants and drug resistance in cancer patients. The lactones can be applied for pest control alone or in a mixture with other plant regulators, fertilizers, herbicides, or fungicides. The haloenol lactones can be used also in drug delivery systems. ${ }^{14}$

In this paper we describe the preparation of fifteen compounds and evaluate their phytotoxic activity against wheat coleoptiles, with the exception of compounds 6 and 7 .

\section{Experimental}

\section{General procedures}

5-hydroxyfuran-2(5H)-one 1 (Figure 2) was prepared from furfural as described in the literature. ${ }^{15}$ Solvents were distilled before use and dried according to standard procedures. Infrared (IR) spectra were performed in a FTIR Varian 660 equipped with GladiATR. Nuclear magnetic ressonance (NMR) spectra were recorded on Varian Mercury 300 spectrometer with deuterated chloroform $\left(\mathrm{CDCl}_{3}\right)$ as solvent and internal standard $(\delta 7.25)$. Chemical shifts $(\delta)$ are given in ppm, and coupling constants $(J)$ in $\mathrm{Hz}$. The assignments of signals for the novel compounds were carried out by nuclear overhauser effect (NOE) and 2D experiments (correlated spectroscopy (COSY) and heteronuclear chemical shift correlation (HETCOR)). Gas chromatography-mass spectrometer (GC-MS) experiments were performed with a Shimadzu QP5050A mass spectrometer, coupled to a Shimadzu GC-17A gas chromatograph (BD5 capillary column, $30 \mathrm{~m}$ ), $70 \mathrm{eV}$. Melting points were obtained on a MQAPF-302 melting point apparatus and were not corrected.

\section{Bioassay}

The wheat coleoptile straight growth test was used for the bioassay. Wheat seeds (Triticum aestivum) were 

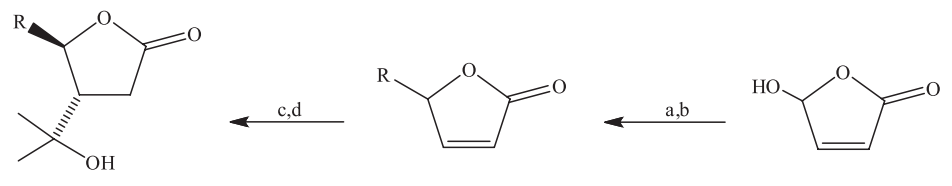

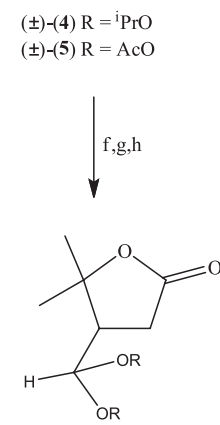

(7) $2 \mathrm{RO}=\mathrm{O}=$ (8) $\mathrm{R}=\mathrm{Me}$
(9) $\mathrm{R}=\mathrm{Et}$

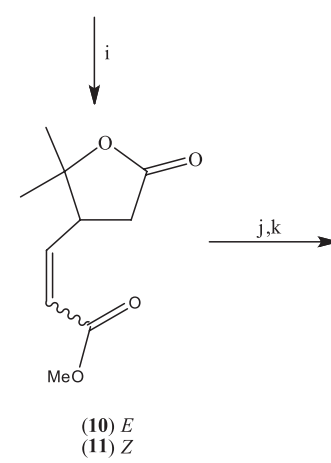

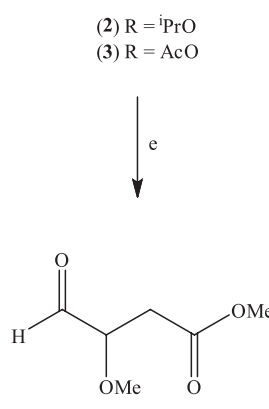

(6)

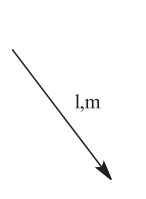

(1)

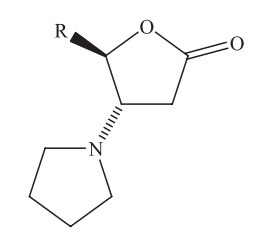

(士)-(14) $\mathrm{R}={ }^{\mathrm{i}} \mathrm{PrO}$ $( \pm)-(15) \mathrm{R}=\mathrm{AcO}$

Figure 2. Reagents and conditions: (a) $p$-toluenesulfonic acid, ${ }^{\mathrm{P}} \mathrm{PrH}$, reflux, 61\%; (b) $\mathrm{Ac}_{2} \mathrm{O}, \mathrm{DMAP}, \mathrm{DCM}, 95 \%$; (c) ${ }^{\mathrm{i}} \mathrm{PrOH}, \mathrm{h} v 210 \mathrm{~nm}$, quartz tube, $91 \%$ of 4 from 2; (d) ${ }^{\mathrm{PrOH}}$, hv $210 \mathrm{~nm}$, quartz tube, $99 \%$ of 5 from 3; (e) Dry MeOH, benzophenone, hv $354 \mathrm{~nm}$, borosilicate reactor, $58 \%$ from 2; (f) MeOH, $\mathrm{H}_{2} \mathrm{SO}_{4}(30 \%), 15 \%$ of 7 and $48 \%$ of $\mathbf{8}$ from 4; (g) EtOH, $\mathrm{H}_{2} \mathrm{SO}_{4}(30 \%), 28 \%$ of 7 and $54 \%$ of $\mathbf{9}$ from 4; (h) $\mathrm{MeCN}_{2} \mathrm{H}_{2} \mathrm{SO}$ ( $30 \%$ ), $50 \%$ of 7 from 4; (i) Trimethyl Phosphonoacetate, 'BuOK, THF, $42 \%$ yield calculated from 4; (j) EtOAc, $\mathrm{H}_{2}, \mathrm{Pd} / \mathrm{C}, 98 \%$ of 12; (k) EtOAc, $\mathrm{H}_{2}$, Pd/C, filtered through acidic celite $49 \%$ of $\mathbf{1 2}$ and $49 \%$ of 13; (1) Dry pyrrolidine, DCM, $65 \%$ of $\mathbf{1 4}$ from 2; (m) Dry pyrrolidine, DCM, $6 \%$ of $\mathbf{1 5}$ from 3.

sown on $15 \mathrm{~cm}$ diameter Petri dishes fitted with moist filter paper and grown at $25^{\circ} \mathrm{C}$ in the dark for 3 days. Coleoptiles 25 to $35 \mathrm{~mm}$ long were selected under a green safelight. A $3 \mathrm{~mm}$ section from the tip was cut off and discarded and the next $4 \mathrm{~mm}$ was selected for the bioassay. After cutting, the coleoptiles were kept in distilled water for $1 \mathrm{~h}$, then selected at random and placed in vials containing the test solutions. Cutting was done with a Van der Weij coleoptile guillotine.

Fractions were tested at 1000, 600, 300, 100, 30 and $10 \mu \mathrm{mol} \mathrm{L}^{-1}$ in a buffered nutritive aqueous solution (citric acid-sodium hydrogen phosphate buffer, $\mathrm{pH}$ 5.6; $2 \%$ sucrose). Stock solutions were prepared in dimethylsulphoxide (DMSO) and diluted to the proper concentration with the buffer to a $0.5 \% \mathrm{v} / \mathrm{v}$ DMSO final maximum concentration. Following dilutions were prepared maintaining the same buffer and DMSO concentrations. Bioassays were performed in $10 \mathrm{~mL}$ test tubes as follows: five coleoptiles were placed per tube containing $2 \mathrm{~mL}$ of test solution each; three replicates were prepared for each test solution. Test tubes were placed in a roller tube apparatus and rotated at $6 \mathrm{rpm}$ for $24 \mathrm{~h}$ at $22^{\circ} \mathrm{C}$ in the dark. Increments of coleoptile elongation were measured by digitalization of their photographic images and data were statistically analyzed.

Statistical analysis of data was obtained using the software GraphPad Prism ${ }^{\circledast}$ version 5. The data were evaluated by the percentage difference of growth provided by each treatment compared to control, so that positive values imply stimulation and negative values imply inhibition of growth.

\section{Results and Discussion}

The 5-hydroxyfuran-2(5H)-one $\mathbf{1}$, which was obtained by photo-oxidation catalyzed by rose bengal of furfural, ${ }^{15}$ was protected to afford 5-isopropoxyfuran-2 $(5 H)$ one 2 and 5-acetoxyfuran-2(5H)-one 3 (Figure 2). Photochemical addition of isopropyl alcohol to lactones 2 and 3 employing low pressure mercury lamps (4 × 15 watts) formed 4-(1'-hydroxy-1'-methylethyl)-5- 
sopropiloxytetrahydrofuran-2-one 4 and 4-(1'-hydroxy1 '-methylethyl)-5-acetoxytetrahydrofuran-2-one $\mathbf{5}$ in 91 and $99 \%$ yield respectively. ${ }^{16}$ The photochemical addition of methanol to lactone $\mathbf{2}$ did not result in the expected photoadduct but in the acyclic ester methyl 3-methoxy-4oxobutanoate 6 ( $58 \%$ yield).

Lactone 4 rearranged to 4-formyl-5,5-dimethyltetrahydrofuran-2-one 7 under acidic conditions with yields varying from 15 to $50 \%$ depending on the solvent employed in the reaction. In this reaction, the formation of acetals 4-(dimethoxymethyl)-5,5-dimethyltetrahydrofuran-2-one 8 and 4-(diethoxymethyl)-5,5-dimethyltetrahydrofuran2-one 9 were also observed with yields of 48 and 54\%, respectively (Table 1 - Supplementary information). To avoid acetal formation acetonitrile was used as solvent. The unstable aldehyde 7 was not purified before the next step. The aldehyde formation was indicated by the characteristic signals observed at $\delta 9.76$ and 197.5 in the ${ }^{1} \mathrm{H}$ and ${ }^{13} \mathrm{C} \mathrm{NMR}$ spectra respectively.

Treatment of aldehyde 7 with the phosphonate carbanion prepared in situ from the reaction between potassium tert-butoxide and trimethyl phosphonoacetate led to the alkenes (Z)-methyl 3-(2,2-dimethyl-5-oxotetrahydrofuran3-yl)acrylate 10 and (E)-methyl 3-(2,2-dimethyl-5oxotetrahydrofuran-3-yl)acrylate $\mathbf{1 1}$ in $42 \%$ yield.

The mixture of alkenes were catalytically hydrogenated to the methyl 3-(2,2-dimethyl-5-oxotetrahydrofuran-3-yl) propanoate 12 in $98 \%$ yield. When the reaction mixture was filtrated under vacuum through acidic celite the 3-(5-oxotetrahydrofuran-3-yl)propanoic acid $\mathbf{1 3}$ was obtained also ( $49 \%$ yield).

5-Isopropoxy-4-(pyrrolidin-1-yl)tetrahydrofuran-2-one 14 and 5-acetoxy-4-(pyrrolidin-1-yl)tetrahydrofuran-2-one $\mathbf{1 5}$ were obtained by conjugated addition of pyrrolidine to 5-isopropoxyfuran-2(5H)-one 2 and 5-acetoxyfuran-2(5H)one 3 respectively.

With exception of compounds $\mathbf{6}$ and 7 , all lactones were evaluated against the growth of wheat coleoptiles.

The most active compounds at $1000 \mu \mathrm{mol} \mathrm{L} \mathrm{L}^{-1}$ were 1, 2 and $\mathbf{3}$ with 51, 76 and $68 \%$ inhibition respectively (Figure 3). Macias et al. ${ }^{13}$ have found previously that $\alpha, \beta$-unsaturated sesquiterpene lactones (SLs) presented the best herbicidal activities. Data clearly show that the same conclusion is valid for small lactones like those tested in the present work. The $\alpha, \beta$-unsaturated lactone act as an electrophilic center for any bionucleophile from enzymes, proteins or any other biological target. However, the presence of an $\alpha, \beta$-unsaturated carbonyl system is not enough to exert an inhibitory effect. The $\alpha, \beta$-unsaturated esters $\mathbf{1 0}$ and $\mathbf{1 1}$ presented only discrete inhibitory growth activities (29 and 18\%; Figure 4) at $1000 \mu \mathrm{mol} \mathrm{L} \mathrm{L}^{-1}$.

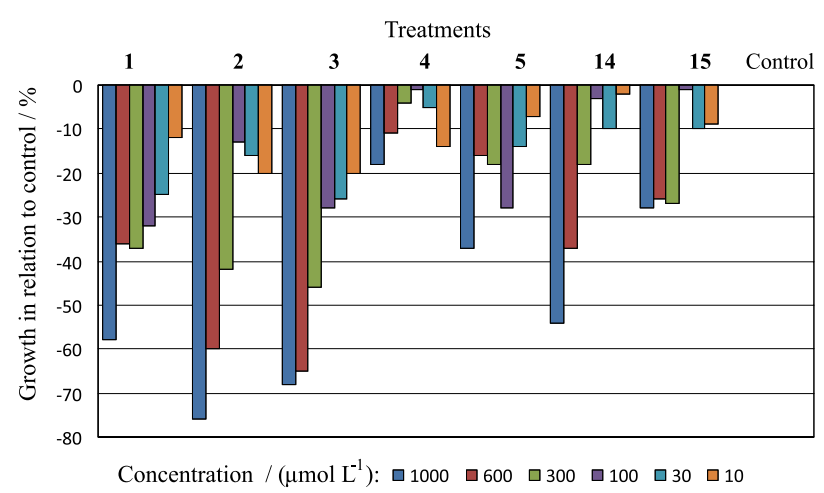

Figure 3. Growth (\%) in relation to control of lactones 1-5, 14 and 15 on the growth of wheat coleoptiles (Triticum aestivum).

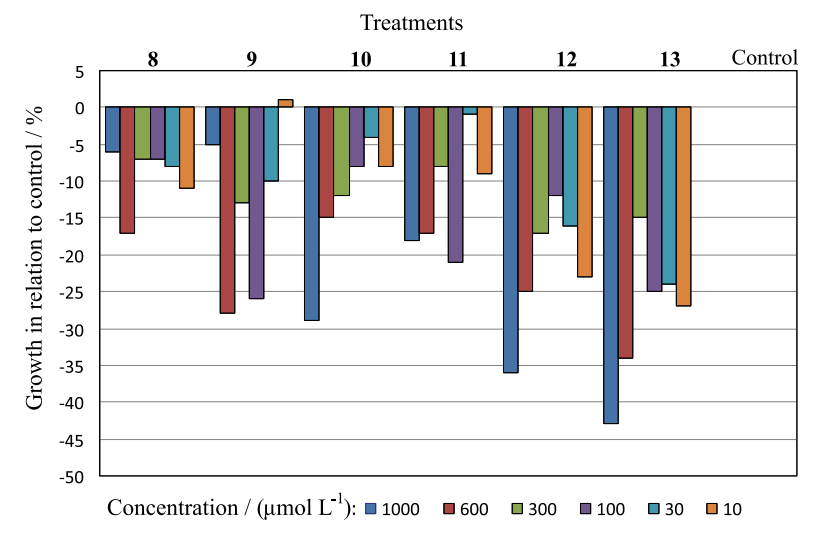

Figure 4. Growth (\%) in relation to control of lactones 8-13 on the growth of wheat coleoptiles (Triticum aestivum).

Among the three most active compounds, lactone 1 was the least active. The phytotoxic activity seemed to decrease with increase in polarity. The presence of a protecting group on the hydroxyl increase lipophilicity of the lactone and phytotoxic activity. The more lipophilic lactones $\mathbf{2}$ and $\mathbf{3}$, bearing the isopropyl and acetyl group, respectively, cross the cell membrane from the coleoptiles more easily than the more polar lactone $\mathbf{1}$. These results are in good agreement with those previously obtained with SLs in coleoptiles and fit the Hansch's model. ${ }^{17}$ Accordingly, modifications introduced as side chains to the unsaturated lactone ring do not interfere with the reactivity of the bioactiphore, but facilitates transport through membranes. This is of special importance in small systems like coleoptiles where no active transport takes place. We have observed also that compounds within the same class with the isopropyl group presented the best results. This could be due to the higher lipophilic character of this group.

Finally, amine $\mathbf{1 4}$ was the most active after compounds $\mathbf{1 , 2}$ and $\mathbf{3}$. This is probably due to the nucleophilic character of the nitrogen from pyrrolidine. A future work would be to vary the protecting group such as to increase (or decrease) polarity of the lactones. 


\section{Conclusions}

The readily available furfural has been employed as starting material for the synthesis of nine novel $\gamma$-lactones out of a total of fifteen compounds. Reasoning regarding the structure-activity relationship of these compounds was conducted employing the coleoptiles bioassay.

The presence of the $\gamma$-lactone ring does not necessarily imply any activity; however its absence seems to hinder activity. The most lipophilic compounds were the most active compounds; however polarity is not necessarily the only factor affecting phytotoxicity.

\section{Supplementary Information}

Supplementary data, infrared, ${ }^{1} \mathrm{H}$ and ${ }^{13} \mathrm{C}$ NMR spectra (Figures S1- S41) for the synthesized compounds are available free of charge at http://jbcs.sbq.org.br as PDF file.

\section{Acknowledgements}

The authors gratefully acknowledge the financial support from the Brazilian agencies CNPq and FAPEMIG. We are grateful to Daniel Pattoni for the English proofreading.

\section{References}

1. Pitelli, R. A.; Série Técnica IPEF 1987, 4, 1.

2. Nougadere, A.; Reninger, J. C.; Volatier, J. L.; Leblanc, J. C.; Food Chem. Toxicol. 2011, 49, 1484; Boutin, C.; Aya, K. L.; Carpenter, D.; Thomas, P. J.; Rowland, O.; Sci. Total Environ. 2012, 415, 79.

3. Powles, S. B.; Yu Q.; Annu. Rev. Plant Biol. 2010, 61, 317.

4. Zambolim L.; Plant Defense, 2010, Special Ed. Science, 86.

5. Bouwmeester, H. J.; Matusova, R.; Sun, Z.; Beale, M.; Rani, K.; US pat. 200901781582009 (CA 145:331794); Tadao, A.; Shinsaku, I.; Kosuke, F.; Takeshi, N.; Pub. No. WO 2012043813 2012 (CA 156:477464).
6. Vestby, L. K.; Stensrud, J. L.; Moretro, T.; Langsrud, S.; Scheie, A. A.; Benneche, T.; Nesse, L. L.; J. Appl. Microbiol. 2010, 108,771 .

7. Arantes, F. F. P.; Barbosa, L. C. A.; de Alvarenga, E. S.; Demuner, A. J.; Bezerra, D. P.; Ferreira, J. R. O.; Costa-Lotufo, L. V.; Pessoa, C.; Moraes, M. O.; Eur. J. Med. Chem. 2009, 44, 3739.

8. Xiao, W.; Li, X.; Li, N.; Bolati, M.; Wang, X.; Jia, X.; Zhao, Y.; Fitoterapia 2011, 82, 983; Chao, W. W.; Kuo, H. K.; Lin, B. F.; J. Agric. Food Chem. 2010, 58, 2505.

9. Husain, A.; Khan, M. S. Y.; Hasan, S. M.; Alam, M. M.; Eur. J. Med. Chem. 2009, 40, 1394.

10. Nogueira, C. R.; Lopes, M. X.; Molecules. 2011, 16, 2146 ; Saxena, S.; Pant, N.; Jain, D. C.; Bhakuni, R. S.; Curr. Sci. 2003, 85, 9.

11. Olejniczak, T.; Boratynski, F.; Bialonska, A.; J. Agric. Food Chem. 2011, 59, 6071.

12. Sosa, M. E.; Tonn, C. E.; Phytochem. Rev. 2008, 7, 3.

13. Zhang, Y. L.; Ge, H. M.; Li, F.; Song, Y. C.; Tan, R. X.; Chem. Biodiv. 2008, 5, 2402; Yoneyama, K.; Awad, A. A.; Xie, X.; Yoneyama, K.; Takeuchi, Y.; Plant Cell Physiol. 2010, 51, 1095; Nicotra, V. E.; Ramacciotti, N. S.; Gil; R. R.; Oberti, J. C.; Feresin, G. E.; Guerrero, C. A.; Baggio, R. F.; Garland; M. T.; Burton, G.; J. Nat. Prod. 2006, 69, 783; de Alvarenga, E. S.; Barbosa, L. C. A.; Saliba, W. A.; Arantes, F. F. P.; Demuner, A. J.; Quim. Nova 2009, 32, 401; Macias, F. A.; Galindo; J. C. G.; Castellano, D.; Velasco, R. F.; J. Agric. Food Chem. 1999, 47, 4407.

14. Jones, A. D.; Mitchell, A. E.; Hammock, B. D.; Zheng, J.; US pat. 6495370. 2002. (CA 126:14753).

15. Moradei, O. M.; Paquette, L. A.; Org. Synth. 2003, 80, 66.

16. Ohga, K.; Matsuo; T.; J. Org. Chem. 1974, 39, 106; Hoffmann, N.; Tetrahedron: Asymm. 1994, 5, 879.

17. Macias, F. A.; Velasco, R. F.; Castellano, D.; Galindo, J. C. G.; J. Agric. Food Chem. 2005, 53, 3530.

Submitted: May 3, 2012

Published online: January 30, 2013 